\title{
El juez de vigilancia penitenciaria en España, como referente de la ejecución penal en América Latina*
}

\author{
Omar Huertas Díaz" \\ Cristina Rumbo Bonfil \\ Alicia Uribe Taborda
}

Recibido: 6 de septiembre de $2017 \cdot$ Aprobado: 15 de octubre de 2017

\section{Resumen}

Si bien la cárcel es la pena más antigua y opresora que ha sido implementada en el mundo, infortunadamente aún no existe una pena que pueda reemplazar el ejercicio y función de esta, son los jueces de vigilancia penitenciaria los que en

* Artículo de investigación desarrollado en el marco de la colaboración entre los grupos de investigación "Escuela de Derecho Penal Nullum Crimen Sine Lege UN", de la Universidad Nacional de Colombia, reconocido y clasificado en A por Colciencias 2017, doctorado en Derecho y Globalización de la Universidad Autónoma del Estado de Morelos UAEM-Cuernavaca (México) y la Facultad de Derecho de la Universidad Central del Valle, Colombia - UCEVA. Proyecto "Debates criminológicos y dogmáticos entre el derecho penal clásico y el derecho penal moderno", financiado por la Facultad de Derecho, Ciencias Políticas y Sociales, Universidad Nacional de Colombia, Proyectos UNIJUS código 37706. DOI: https://doi.org/10.15332/s1900-0448.2018.0048.03

" Abogado, investigador y profesor asociado, especialista en Derecho Penal y candidato a doctor en Derecho, Universidad Nacional de Colombia, Ph. D. en Ciencias de la Educación, Universidad Simón Bolívar, Barranquilla, Colombia. Magíster. en Derecho Penal, Universidad Libre, Bogotá, Colombia, magíster en Derechos Humanos, Estado de Derecho y Democracia en Iberoamérica, Universidad de Alcalá, España, magíster en Educación, Universidad Pedagógica Nacional. Socio de la Fundación Internacional de Ciencias Penales FICP. Miembro de honor de la Fundación de Victimología. Miembro honorario Asociación Colombiana de Criminología. Correo electrónico: ohuertasd@unal.edu.co

*- Magíster en Derecho y doctorante en Derecho y Globalización, Universidad Autónoma del Estado de Morelos-México. Ha realizado múltiples estudios y trabajos y estancias de investigación en el tema del sistema carcelario y ejecución penal en México, Colombia (Universidad Nacional), España (Universidad de Valencia) e Italia (Universidad de Trento).Correo electrónico: lic.cristinarb@gmail.com

*-* Abogada y especialista en Derecho Constitucional, Universidad Central del Valle, Colombia, magíster en Derechos Humanos, Estado de Derecho y Democracia en Iberoamérica, especialista en Derecho Procesal Civil, Universidad Externado de Colombia. Decana Universidad Central del Valle, Colombia - UCEVA. Correo electrónico auribe@uceva.edu.co 
exclusiva hacen ejecutar lo juzgado en ejercicio de la potestad jurisdiccional, y con ello cumplen no solo con el mandamiento judicial determinado en una sentencia, sino también cumplen con lo consagrado en el mandato constitucional y se convierte en automático en un ente garante de los derechos de las personas privadas de la libertad, teniendo la gran labor de reivindicar la función jurídico-estatal de las instituciones penitenciarias.

Es de vital importancia analizar la creación y función de esta figura dentro del sistema penitenciario en España, que en mucho ha servido de ejemplo para países latinoamericanos como México y Colombia, y que ha dado la pauta de la instauración de un moderno modelo de ejecución penal.

Palabras clave: juez de vigilancia penitenciaria, ejecución penal, sistema carcelario, privación de la libertad, derechos humanos.

\title{
The judge of Penitentiary surveillance in Spain, as a BENCHMARK FOR CRIMINAL ENFORCEMENT IN LATIN AMERICA
}

\begin{abstract}
Although prison is the oldest and most oppressive penalty that has been implemented in the world, unfortunately there is still no penalty that can replace its exercise and function, penitentiary surveillance judges are the ones who exclusively enforce what is sentenced in the exercise of the jurisdictional power, and thus comply not only with the judicial order determined in a sentence but they also comply with what is stipulated in the constitutional mandate and becomes automatic in a body that guarantees the rights of persons deprived of liberty, having the great task of vindicating the legal-state function of penitentiary institutions.

It is of the utmost importance to analyze the creation and function of this figure within the penitentiary system in Spain, which has served as an example for Latin American countries such as Mexico and Colombia, and has set the standard for the establishment of a modern model of criminal enforcement.
\end{abstract}

Keywords: Judge of penitentiary surveillance, criminal enforcement, penitentiary system, deprivation of liberty, human rights. 


\section{O JUIZ DE VIGILÂNCIA PENITENCIÁRIA NA EsPANHA, COMO REFERENTE da EXeCUÇÃo PENAL Na América Latina}

\section{Resumo}

A prisão e punição mais antiga e opressora que tem sido implementada no mundo, infelizmente, ainda não existe uma pena que possa substituir o exercício e a sua função. São os juízes de vigilância penitenciária os quais fazem executar o julgado em exercício da potestade jurisdicional, com isso cumprem não só o mandamento judicial determinado em uma sentencia, senão também cumpre com o estabelecido no mandado constitucional e converte-se em um ente garante dos direitos das pessoas privadas da liberdade, tendo como grande tarefa de reivindicar a função jurídico-estatal das instituições penitenciárias.

É muito importante analisar a criação e função desta figura dentro do sistema penitenciário na Espanha, que tem sido um grande exemplo para países latino-americanos como o México a Colômbia e tem dado a pauta da instauração de um modelo moderno de execução penal.

Palavras-chave: juiz de vigilância penitenciária, execução penal, sistema carcerário, privação da liberdade, direitos humanos.

\section{Metodología}

Una teoría sin métodos es torpe y un método sin teoría es ciego (González, 2014). Es por ello que para el estudio y desarrollo de esta investigación, se ha estimado la utilización de varios métodos de investigación científica para recolectar la información necesaria. Para el caso específico de esta investigación, el análisis es o se enfoca en un grupo en específico: las personas internas en un centro penitenciario, privadas de la libertad por la comisión de un acto ilícito y sancionado por el Estado. En todo caso, no se entrará a estudiar cuáles fueron las razones que llevaron a estas personas a cometer dicho acto, pero sí cuáles son las circunstancias que cohabitan con miles de internos que por diferentes circunstancias también se encuentran o comparten una situación similar.

En todo caso, el problema penitenciario visto desde un enfoque sociológico ofrece una amplia perspectiva respecto a qué y cómo debe estudiarse dicho problema; puesto que el fenómeno social debe comprender a los sujetos que hacen parte de este y de cómo interaccionan para propiciar ciertas situaciones que lo van consolidando, 
para el caso penitenciario el factor social es predominante, tratándose de personas que en apariencia han sido apartadas de cualquier contacto social. Por esta misma razón, el sistema carcelario habrá de estudiarse sistemática, metodológica, social y normativamente para comprenderse y desentrañarse para saber cuáles son los motivos que no permiten que estos centros sean saneados y cumplan los objetivos para los cuales fueron creados.

\section{Introducción}

La jurisdicción penitenciaria presenta tres vertientes de actuación muy diversa: en primer lugar, responde al ya indicado propósito de judicializar la ejecución, es decir, el reforzamiento de la garantía de ejecución, convirtiéndola de administrativa en judicial, o si se prefiere, judicializando por completo lo que antes solo estaba en una pequeña parte.

En segundo lugar, el juez de vigilancia penitenciaria se convierte en el garante del correcto funcionamiento de los establecimientos penitenciarios, al menos en aquellos casos que más directa y particularmente afecten a los derechos de los internos. Finalmente tiene atribuida la facultad de formar propuestas a la administración penitenciaria en aquellas materias relativas a actividades regimentales, económico administrativas y de tratamiento penitenciario en sentido estricto.

Sin embargo, la ejecución penal con sus deficiencias en los diversos modelos carcelarios permite en una perspectiva más moderna, que la pena pueda cumplirse en un estricto apego a las normas internacionales de protección de derechos humanos, permitiendo que se aleje de la vieja maquinaria de aplastamiento de la dignidad humana como antiguamente se concebía. También se ha permitido la adopción de mecanismos más estrictos de control judicial, que inhiben la voluntad de la administración penitenciaria y conllevan la vigilancia en la ejecución y la participación del sentenciado, que habrá de conocer en todo momento la situación que guarda su proceso y le permitirán acceder a programas reeducativos para su correcto retorno a la sociedad.

Todo lo anterior atendiendo en primera instancia a que en Colombia se evidencia, como lo indica Romero (2017):

Excesos en la restricción de la libertad de las personas sindicadas, el hacinamiento carcelario, el aumento en el índice de construcción de penitenciarias y el 
desconocimiento al interior de las mismas de un sinnúmero de derechos humanos para quienes están presos, al tiempo de influir en la congestión en el sistema judicial propiciándose con ello trabas que impiden la celeridad de la justicia y aumentan los índices de impunidad. (p. 92)

En tercera instancia, a que el concepto clásico del Derecho Penal se ha desnaturalizado, entendiendo por tal, "la herramienta de naturaleza coercitiva que posee el Estado con el fin, en principio, de prevenir conductas de naturaleza reprochable" (Valderrama, 2016, p. 160).

\section{La judicialización de la ejecución penal y la función de la pena}

La judicialización de la ejecución penal ha sido un tema de creciente preocupación, no solo a partir del siglo XX sino incluso antes. La justificación de la imposición de la pena ha tenido la imperiosa tarea no solo de ser justa o legitima, sino también de encontrar una justificación para la misma. Por tanto, el cumplimiento en la ejecución de las penas ha venido perfeccionarse aún más a partir de este nuevo siglo, con la incorporación y observancia de los derechos humanos, a través de un proceso de positivación de los mismos; la administración de justicia ha tenido luego entonces - la difícil tarea de la justificación en la imposición de las penas.

La justificación de la ejecución de las penas no es sino un proceso determinado a partir del principio de legalidad que en términos prácticos permite la judicialización de la ejecución de las sanciones, y con ello se da la pauta a la creación de órganos de vigilancia que den pleno cumplimiento a la sanción impuesta por el tribunal competente, siguiendo no solo criterios judiciales o administrativos, sino incluso de protección de derechos fundamentales.

La plasmación del principio de legalidad es doble: por un lado, produce la exclusión de conductas arbitrarias en un ámbito particularmente sensible a la vulneración de los derechos fundamentales; por otro, vincula a los órganos unipersonales y pluripersonales que participan en la ejecución de la pena de prisión y en su supervisión al respeto a las normas que la regulan. En la ejecución penal, es el estado quien se convierte en garante del cumplimiento del principio de legalidad y del respeto de los derechos fundamentales dentro de esa relación de mayor intensidad que liga al 
interno con la administración penitenciaria, denominada como relación de especial sujeción (Rodríguez, 2013).

Sin embargo, la teoría de especial sujeción ha probado en países como Alemania (que tanto ha servido de ejemplo a la legislación española) la necesaria justificación de un modelo de ejecución penal que no solo atienda la normativa vigente, sino que además apele a los derechos de las personas recluidas dentro de las prisiones, el derecho probado de estas personas no se mantiene más en una fase limitativa, sino de suspensión de algunos de sus derechos civiles y políticos. Como lo probará la tesis jurisprudencial del Tribunal Constitucional alemán del 14 de marzo de 1972 (Rivera, 1999), en ella se deja a un lado la teoría de la relación especial de sujeción para declarar que no será constitucional una limitación de los derechos fundamentales de la persona con base a una norma de rango administrativo o montada a lograr ya sea los fines de la pena y del establecimiento penitenciario.

Con ello el peso de la autoridad estatal y penitenciaria e incluso del legislador, recae no solo en el perfeccionamiento de los modelos de imposición penal o incluso en el proceso mismo, sino que se extiende necesariamente en la ejecución de la penalidad impuesta, los modelos arcaicos de penas que laceraban cualquier posibilidad de respeto a los derechos humanos y a la dignidad de la persona, han sido superados al menos doctrinariamente, hoy se requiere un sistema garante de protección a los derechos fundamentales, que evite la doble victimización y restrinja en lo mínimo posible la voluntad humana.

$\mathrm{Al}$ aceptarse esta tesis no se puede dejar entonces de estar plenamente de acuerdo con todas las consideraciones que entienden a la fase ejecutiva-penal, como aquella en la cual, por no existir una presencia activa y firme del control jurisdiccional, menos se respetan las garantías, puesto que a casi nadie le preocupa qué pasa después de dictada una sentencia.

Mucha de esa responsabilidad — hoy día — recae en la figura de los jueces que se encargan ya no solo de dictar las sanciones, sino también de vigilar su correcto cumplimiento. Son los jueces de vigilancia penitenciaria, los que en exclusiva hacen ejecutar lo juzgado en ejercicio de la potestad jurisdiccional y con ello cumplen no solo con el mandamiento judicial determinado en una sentencia, sino también cumplen con lo consagrado en el mandato constitucional y se convierte automáticamente en un ente garante de los derechos de las personas privadas de la libertad, teniendo la gran labor de reivindicar la función jurídico-estatal de las instituciones penitenciarias. 
Aun con todo ello, la figura jurisdiccional del juez de vigilancia penitenciaria tiene, todavía, muchos retos que cumplir, especialmente debido a que el sistema penitenciario tiene a cuestas décadas de una ineficacia administrativa y legislativa, que ha permitido históricamente un sin número de vejaciones y violaciones de los derechos humanos de los sentenciados y privados de la libertad. Específicamente esta figura que es estrictamente novedosa, ha sido creada por la imperiosa necesidad de terminar con esa fase injusta e inhibidora que fue y que aún es en algunos países del mundo la cárcel.

Por ello, es de vital importancia que se analice su creación y función dentro del sistema penitenciario en España, que en mucho ha servido de ejemplo para países latinoamericanos como México y Colombia, y que ha dado la pauta de la instauración de un moderno modelo de ejecución penal, que pretende apegarse a los estándares internacionales de protección de derechos y con ello, como ya lo hemos mencionado, sanear el sistema añejo y dar cabida a uno que permita una correcta implementación de las penas y medidas de seguridad.

Si bien la cárcel es la pena más antigua y opresora que ha sido implementada en el mundo, infortunadamente aún no existe una pena que pueda reemplazar el ejercicio y función de esta, por tanto es preciso buscar que la pena de prisión sea lo menos restrictiva y permita salvaguardar en lo posible la dignidad de aquellos que han cometido una conducta antijurídica y que merezcan por ello ser sancionados por la autoridad judicial.

\section{El juez de vigilancia penitenciaria, caso España}

La población reclusa en España hasta el 2015 (SGIP, España, 2016), era de un total de 52.804 internos, de los cuales 48.691 eran hombres y 4.113 mujeres. España tiene una tasa de delincuencia comparativamente baja comparada con aquellos países donde el hacinamiento hace mella en el sistema carcelario, sin embargo, es uno de los países de la Unión Europea con mayor número de personas encarceladas (120 por cada 100.000 habitantes frente a 90 como media). Por ello, no es razonable que se impulse o se apoye un conjunto de reformas, que no se justifican por la finalidad de dar una respuesta justa y efectiva a la delincuencia, sino por la voluntad política de rentabilizar electoralmente el uso y la duración del encarcelamiento.

$Y$ es que lo que sucede en España, sucede en México o en Colombia, donde este último tiene una de las crisis penitenciarias más dolorosas de América Latina, 
siendo el excesivo uso de la pena privativa de la libertad la pena rectora, identificando así a ambos países (Huertas, 2015). Si bien en España las condiciones de "crisis" y de "prisión" no son las mismas a las que se viven en México, lo son en el sentido de la política criminal que da origen a la pena y con ello a la ejecución de la misma. En México casi el $80 \%$ de las personas internas en un centro penitenciario se encuentran por conductas de las consideradas no graves, lo cual pone en entre dicho la justificación de la pena de prisión como un mecanismo eficaz y eficiente para inhibir las conductas delictivas, pero específicamente para alcanzar la reinserción del sentenciado.

La figura del juez de vigilancia penitenciaria ha evidenciado en ambos países la necesidad de buscar alternativas tendientes a la sanción de las figuras típicas y punibles, sin embargo, se ha de reconocer que España aún y cuando tiene la tasa más alta de personas recluidas en Europa, ha hecho las cosas un tanto mejor que México, donde la figura del juez de ejecución de sanciones representa una figura novedosa, con la que se pretende sanear a largo plazo el corrompido sistema carcelario.

En este sentido existen algunas cuestiones a considerar, pues la figura del juez de vigilancia penitenciaria sigue arrastrando el estigma funcional de la ejecución de la pena, ¿para qué sirve la prisión?, ¿existe realmente un tratamiento resocializador del individuo privado de la libertad?, ¿es realmente el juez de ejecución un ente garante de los derechos de las personas privadas de la libertad? Estas entre muchas otras son las interrogantes que surgen al abordar el problema penitenciario y con ello la creación de una figura especializada en la vigilancia de la ejecución penal.

Es importante revisar las atribuciones contenidas legislativamente en la figura del juez de vigilancia español y determinar en el uso de esas facultades cuáles son los atisbos que pueden eficientar y servir de ejemplo para mejorar aún más la ejecución punitiva en este y en todos aquellos países donde se piensa no solo en un estado con un mínimo uso de la pena, sino con una efectiva ejecución de la misma.

El juez de vigilancia penitenciaria en España puede ser visto hoy día como una figura jurídica que pretende reivindicar el concepto de ejecución penal, que además propicie sustitutivos de la misma y por ende ejercite las medidas de seguridad tendientes al uso alternativo de sustitutivos penales.

Al igual que ha pasado en muchos de los sectores jurídicos en los que el derecho internacional y el reconocimiento de los derechos humanos influyó a partir del siglo XX, la ejecución penal contenía una crisis administrativa y humanística, se 
necesitaba de un control externo y ajeno a la administración que tuviera la finalidad de supervisar la actuación gubernativa (Cervelló, 2016).

Bajo ese supuesto y con la directriz de las reglas de Mandela, surge la idea de un órgano de vigilancia con funciones que permitan una modificación en la ejecución de las penas y la protección de los derechos humanos. Es pues el juez de vigilancia penitenciaria el órgano judicial que fue creado con el firme propósito de tener una participación en el proceso ejecutivo penal y no únicamente como un ente jurisdiccional, aunque claramente lo sea.

La figura del juez de ejecución de sanciones o como también se le conoce tradicionalmente en países europeos (España por ejemplo) juez de vigilancia penitenciaria, tiene una participación medular no solo en la ejecución de la sanción, sino esencialmente en la procuración y respeto de los derechos humanos y garantías jurídicas de las personas privadas de la libertad. En algunos países latinoamericanos, la figura es hasta cierto punto novedosa (citando obligatoriamente a México, donde la figura aparece por primera vez a partir de la reforma del 2008 del sistema de justicia penal, donde coyunturalmente a la instauración del nuevo modelo de justicia penal, se adoptó la figura de la ejecución penal configurando de esta manera un modelo de justicia integral que se encargará no solo de la administración de la justicia, sino además de la ejecución efectiva de la pena), lo que ha obligado a estos a revisar y replicar los modelos judiciales que se han implementado en los países europeos (Huertas y Abreu, 2007).

Sin embargo, incluso en España la figura del juez de vigilancia penitenciaria ha sido reciente si se compara con las figuras análogas de países como Italia (1930), Francia (1944-1945) o Portugal (1944), y el caso excepcional de Brasil, que no solo fue el primer país latinoamericano en incorporar la figura, sino en realidad fue el primer país del que se tenga registrado la haya adoptado en una ley federal en 1922, para luego recogerlo en su Código de Procedimiento Penal de 1940 (Martín, 1999).

\section{Facultades y atribuciones del juez de vigilancia}

Esta figura jurídico-judicial apareció por primera vez en la legislación española a partir de la Ley Orgánica General Penitenciaria del 26 de septiembre de 1979, tras la derogación práctica de la Ley de Peligrosidad y Rehabilitación Social de 1970 por el Tribunal Constitucional a partir de las sentencias de 1985, 1986 y 1987 (Racionero, 1999), lo que en consecuencia determinaría la judicialización de 
la ejecución de la sentencia en España, y obedeciendo además al mandato constitucional inserto en el artículo 117.3 de la Constitución española:

3. El ejercicio de la potestad jurisdiccional en todo tipo de procesos, juzgando y haciendo ejecutar lo juzgado, corresponde exclusivamente a los Juzgados y Tribunales determinados por las leyes, según las normas de competencia y procedimiento que las mismas establezcan.

En la ley orgánica del Poder Judicial, también se menciona y se delimitan las funciones atribuidas a la figura del juez de vigilancia penitenciaria (JVP), sin embargo, en el caso específico del JVP, existen variedad de instrumentos que apoyan el ejercicio penitenciario, se describe en sus artículos 94 y 95.

También con la creación de la Ley Orgánica General Penitenciaria que, en su artículo 76, determina al JVP como un órgano jurisdiccional especializado, al que se le atribuyen las competencias de control de la administración en su labor de ejecutar la pena de prisión y que se convierte con ello antes de la aprobación de esta ley, el tribunal sentenciador dictaba la sentencia condenatoria, adoptaba las medidas necesarias para que el reo ingresara en prisión y volvía a intervenir para acordar la excarcelación, esto significa que dentro del recinto carcelario su actividad era prácticamente inexistente hasta el punto que la decisión de una figura tan importante como la concesión de la libertad condicional era tomada por un órgano mixto en el que intervenían tanto autoridades administrativas como judiciales (Cervelló, 2016).

Esta figura jurisdiccional nace con el propósito de "juzgar y hacer ejecutar lo juzgado”, en un órgano judicial independiente e imparcial. Específicamente es el encargado de:

Velar por las situaciones que afecten a los derechos y libertades fundamentales de los presos y condenados, en los términos previstos en los artículos 25.2, 24 y 9.3 de la Constitución española, al construir un medio efectivo de control dentro del principio de legalidad y una garantía de interdicción de la arbitrariedad de los poderes públicos. (Juanatey, 2016)

Sin embargo, se tiene debe precisar que en relación a la jurisdicción de la vigilancia penitenciaria, no es en sí mismo el juez de vigilancia penitenciaria la única 
figura jurídica que podría participar en ese proceso, pues están también de forma enunciativa (Racionero, 1999):

- El Tribunal Sentenciador, sea juzgado de instrucción o de lo penal, las Audiencias Provinciales y la Nacional, las Salas de lo Civil y Penal de los Tribunales Superiores de Justicia y el Tribunal Supremo, cuando actúa con tal carácter.

- El Tribunal Supremo, tanto su Sala II (a efectos del recurso de casación previsto en el art. 988 Ley de Enjuiciamiento Criminal), como el Tribunal y la Sala de Conflictos Jurisdiccionales, para resolver los conflictos surgidos entre la administración civil y la jurisdicción ordinaria y entre la jurisdicción militar y la ordinaria, respectivamente.

- Tribunal Constitucional en vía de amparo.

- Tribunal Europeo de Derechos Humanos.

- Orden jurisdiccional laboral, en cuanto conoce de los conflictos que se deriven de la relación laboral especial penitenciaria (título $\mathrm{V}$, capítulo IV RP), y el contencioso administrativo en todas aquellas materias no expresamente sometidas a los JVP y que tengan que ver con los actos de la administración sujetos al derecho administrativo y con las disposiciones de categorías inferiores a la ley.

De acuerdo con el artículo 76 de la LOGP, la función jurisdiccional de los JVP se puede agrupar en tres ámbitos: aquellas funciones decisorias en las que actúa en primera instancia, otras en las que interviene en segunda instancia resolviendo recursos y otras en las que su cometido es solo tener conocimiento.

$\mathrm{El}$ artículo 76.1. LOGP dispone que, con carácter de general, el juez de vigilancia "tendrá atribuciones para hacer cumplir la pena impuesta"; con esta competencia se confiere un gran protagonismo en el ordenamiento penitenciario español, mismo que ha sido ratificado por el Tribunal Constitucional, cuya función supone una potenciación de la ejecución de la sentencia.

Las facultades del juez de vigilancia penitenciaria están determinadas de acuerdo a la forma en que actúan y deciden, si bien se ha dicho que esta figura surgió como contrapeso de las decisiones tomadas por la administración penitenciaria que pudieren significar violaciones a los derechos fundamentales de las personas privadas de la libertad, las actuaciones de los jueces se determinan con apego a sus funciones 
decisorias y la forma en que da dicha intervención, en ese caso las decisiones pueden darse en primera y segunda instancia. De acuerdo con Cervelló (2016), quien argumenta que las funciones decisorias en primera instancia se refieren a:

a. Conceder la libertad condicional y acordar su revocación (art. 76.2 b).

b. Acordar propuestas de beneficios que supongan acortamiento de la condena (art. $76.2 \mathrm{c})$.

c. Aprobar la imposición de la sanción de aislamiento de más de catorce días (art. $76.2 \mathrm{~d})$.

d. Autorizar la concesión de los permisos de salida de más de dos días excepto de los clasificados en tercer grado (art. 76.2 i).

e. Acordar lo que proceda sobre peticiones y quejas que afecten a los derechos fundamentales formulados por los internos con relación al régimen y tratamiento (art. $76.2 \mathrm{~g}$ ).

En cuanto a las resolutorias en segunda instancia, se tienen:

a. Resolver por vía de recursos las reclamaciones de los internos sobre sanciones disciplinarias (art. $76.2 \mathrm{e}$ ).

b. Resolver los recursos referentes a clasificación inicial y regresión de grado (art. $76.2 \mathrm{f}$ ).

Además, la figura del juez de vigilancia ha tenido que ser dotada paulatinamente de mayores atribuciones que permitan una efectiva tutela y vigilancia del cumplimiento de la pena, una de las reformas que permitieron un mayor control de la ejecución penal es la del Código Penal de 1995.

1. Sanciones de aislamiento.

2. Reclamación sobre sanciones disciplinarias.

3. Resolver recursos referentes a clasificación, progresiones y regresiones de grado.

4. Realizar visitas a establecimientos. 
5. Autorizar permisos de salida.

6. Conocimiento de traslado de reclusos a establecimientos de régimen cerrado.

7. Conocer de violaciones de derechos humanos.

\section{Competencias del juez de vigilancia penitenciaria para la protección de los derechos de los internos}

De acuerdo con el contenido del artículo 76 de la LOGP, se prevén entre las muchas atribuciones que se le han asignado a esta figura, que ejerza un control de las actuaciones de la administración penitenciaria respecto a la organización de los establecimientos, el régimen y el tratamiento. En este caso, es necesario precisar que, en materia de clasificación, tratamiento y permisos, el control jurisdiccional quedará sujeto a la previa interposición de recurso por alguna de las partes legitimadas para ello, en concreto las referentes a (Berdugo, 2016):

a. Aprobar sanciones de aislamiento en celda de duración superior a catorce días (art. 76.2 d LOGP).

b. Resolver por vía de recurso reclamaciones que formulen los internos sobre sanciones disciplinarias (art. 76.2 e LOGP).

c. Acordar lo que proceda sobre peticiones o quejas que los internos formulen con relación al régimen y al tratamiento penitenciario en cuanto afecte a los derechos fundamentales o a los derechos y beneficios penitenciarios de aquellos (art. $76.2 \mathrm{~g}$ LOGP).

d. Realizar visitas a los establecimientos penitenciarios (art. 76.2 h LOGP).

e. Autorizar los permisos de salida cuya duración sea superior a dos días, excepto de los clasificados en tercer grado (art. 76.2 i LOGP).

f. Conocer del pase a régimen cerrado de los reclusos a propuesta del director del establecimiento (art. $76.2 \mathrm{j}$ LOGP). 


\subsection{Los derechos de las personas privadas de la libertad y el derecho al tratamiento de resocializador}

Un tema de suma importancia no solo para el sistema de ejecución española, sino para cualquier otro sistema de ejecución penal, es el que tiene que ver con la protección y el respeto a los derechos humanos de las personas privadas de la libertad. Los DD. HH. suman al sistema de justicia penal y la ejecución de las sanciones y medidas de seguridad un número específico de normas mínimas, que es necesario y obligatorio para los estados atender de acuerdo con el derecho internacional de protección de derechos.

Se ha dicho que durante décadas el sistema penitenciario ha sido sinónimo de injusticia, pues con la incorporación de los DD. HH. se pretende que la pena de prisión evolucione a un mecanismo preventivo más que inquisitivo. Parte de esta nueva concepción ha sido impulsada por el derecho natural y el garantismo que han depositado en la figura del JVP las bases para una ejecución penal justa y retributiva.

Para ello, en España la LOGP ha otorgado competencias al juez de vigilancia penitenciaria, para la protección de los derechos fundamentales de los presos, de una parte, así como la limitación del poder de la administración penitenciaria, de otra, constituyéndose en los pilares para interpretar y aplicar el ordenamiento penitenciario (Pérez, 2016).

El Tribunal Constitucional en la sentencia del 30 de julio de 1983, reconoce al juez de vigilancia penitenciaria la condición de vía normal para salvaguardar los derechos de los internos en las prisiones contra actos de la administración penitenciaria y como, consecuencia de ello, en la sentencia del 26 de abril de 1993, califica a los JVP como pieza clave del sistema penitenciario, exigiendo su intervención como requisito imprescindible para acceso al recurso de amparo, es decir, a los efectos del artículo 43.1 de la LOTC.

E1 Tribunal Constitucional de Alemania niega la existencia en el ámbito penitenciario de relaciones especiales de sujeción. La doctrina y la jurisprudencia coincidieron durante mucho tiempo en considerar que los penados se encuentran sometidos a una relación especial de sujeción de la que deriva un modelo de ejecución no regulado jurídicamente.

Esta orientación político penitenciaria sustentada por una constante jurisprudencia sería alterada por una resolución del TC alemán del 14 de marzo de 1972, en ella se deja a un lado la teoría de la relación especial de sujeción, para declarar que 
no será constitucional una limitación de los derechos fundamentales de la persona con base a una norma de rango administrativo o montada a lograr ya sea los fines de la pena y del establecimiento penitenciario. En efecto a la estructuración jurídicopositiva de los derechos del interno favorece una visión plural y dinámica de la pena y no estática y unidimensional. Las teorías de las relaciones especiales de sujeción se corresponden con una visión retributiva de los fines de la pena (Rivera, 1999).

Por este motivo, pese a que el TC reitera la existencia de una relación especial de sujeción de la misma, no extrae las consecuencias que lógicamente debieran de extraerse, sencillamente porque de hacerlo así haría una reflexión coherente en un plano teórico, pero radicalmente contraria a la legislación penitenciaria e incluso del propio texto constitucional.

Jellinek, quien es el padre de la teoría de las relaciones especiales de sujeción, define a partir del status libertatis, el núcleo de los derechos personales como inherentes a toda persona e inviolables porque son los elementos esenciales para el desarrollo integral de la personalidad, que como señala también la constitución española en todo caso deberán ser respetados durante la ejecución de la pena (Pérez, 1984).

Pese a las declaraciones normativas que señalan que a los reclusos solo se les ha de privar de su libertad, todos y cada uno de sus derechos fundamentales (a la vida, a la salud y a la integridad física y psíquica, a la defensa, al trabajo remunerado, al respeto de su vida privada, al secreto de su correspondencia, etc.) se encuentran "devaluados" en comparación con la tutela que poseen esos mismos derechos cuando los mismos se refieren a quienes viven en libertad.

E1 Tribunal Constitucional Español, en su auto TC 15/1984 del 11 de enero, señaló que la reeducación o la reinserción social del penado no constituye un derecho fundamental de la persona, "sino un mandato del constituyente al legislador para orientar la política penal y penitenciaria, mandato del que no se derivan derechos subjetivos, aunque, como es obvio, pueda servir de parámetro para resolver acerca de la constitucionalidad o inconstitucionalidad de las leyes penales" (Tribunal Constitucional Español).

Esta jurisdicción es tuitiva, o garantista si se prefiere, al tener como uno de sus cometidos esenciales, aunque no único, la protección y tutela de los derechos humanos, fundamentales y ordinarios de los internos en un centro penitenciario, y es también permanente, prolongándose durante la vigencia de la relación jurídica penitenciaria, de tal modo que ni un solo instante de la vida de un interno en un 
centro penitenciario puede estar no sometido a la acción tutelar de un juzgado, si bien, claro es, con arreglo a las normas de competencia territorial (Racionero, 1999).

Salvaguardar los derechos de los internos, se refiere tanto a los derechos fundamentales no limitados por el contenido del fallo condenatorio, el sentido de la pena y el ordenamiento penitenciario, como por ejemplo los permisos de salida, formular peticiones y quejas, vestir sus propias ropas, limitación legal en el uso de medios coercitivos, etc. Las correcciones, abusos y desviaciones en el cumplimiento de preceptos reglamentarios, tiene que ver con la corrección que se limita a los abusos y desviaciones que puedan producirse en el régimen penitenciario. Por tanto, es una facultad amplísima, pues el "régimen" es nada menos que el conjunto de normas que regulan la convivencia y custodia de los internos y el orden dentro de los establecimientos penitenciarios, determinando los derechos y prestaciones que corresponden al recluso por su condición general de ciudadano del Estado (Racionero, 1999).

Los derechos humanos y su aplicación no son limitativos a la conducta atípica, si bien es cierto que una persona puede ser suspendida de sus derechos civiles y políticos en cuanto se encuentre cumpliendo una pena privativa de la libertad, ello de ninguna forma limita sus derechos humanos en condición de persona, las violaciones a estos derechos no solo deben evitarse, sino que corresponde al estado la salvaguarda de los mismos (Huertas, Trujillo y Silvera, 2015).

Los JVP han significado la inclusión del derecho internacional, los tratados internacionales de protección de DD. HH. y el respeto a la dignidad humana dentro del sistema carcelario, esta concepción mínima intenta garantizar el cumplimiento del principio de legalidad y del contenido constitucional con miras al establecimiento de un correcto estado de derecho, es dentro del sistema carcelario donde es más visible esto y donde mayormente se corre el riesgo de incumplir con todo aquello a lo que los estados se comprometen dentro de la comunidad internacional en apego a los derechos humanos.

En suma, la nueva generación de derechos y su aplicación en la eficacia y eficiencia de la ejecución penal, pugna por medidas cada vez menos restrictivas y se apuesta por los mecanismos de prevención y reeducación, confiando en que es posible dar a aquellos que han delinquido, los mecanismos para un retorno saludable a la sociedad y confiando en que el Estado tiene una justificación normativa, pero sobre todo garantista para la imposición de penas, que lejos han quedado de significar solo un castigo para los criminales incorregibles de la sociedad. 


\section{Medios alternativos a la pena privativa de prisión}

Dentro de las atribuciones con que cuenta el JVP, no solo se encuentra la vigilancia en el cumplimiento de las penas, sino además, el aseguramiento de optar y proponer medidas correctivas distintas a la pena de prisión. Al principio de este artículo se mencionaba que uno de los grandes problemas que sufre el sistema carcelario español es el uso excesivo de la pena de prisión, pues bien, este no es problema en exclusivo de España; en México, Colombia y en gran parte de los países latinoamericanos, también se abusa en el uso de la prisión como pena y no se explora el uso de sustitutivos a la misma, gran parte de los códigos penales cuenta con una sanción punitiva carcelaria, tratándose incluso en delitos de naturaleza no grave (fuero común) y en los cuales en la mayoría de los casos se concentra el grueso de la población penitenciaria.

Pues bien, el JVP tiene la gran responsabilidad de proponer el uso alternativo de penas, y buscar que una sanción no grave pueda ser sujeta a un medio alternativo a la prisión y con ello despresurizar el sistema carcelario que en tanto se padece del llamado "hacinamiento penitenciario". Con esto el JVP se convierte en un ente garante y protector del principio de legalidad, pero también en un ente con la responsabilidad de lograr la función social del sistema penitenciario.

Dentro de la legislación española, en el código penal vigente, las posibilidades contempladas que pasan por evitar el ingreso en prisión y con ello evitar el uso excesivo de la misma son, entre otras, las siguientes:

- Pena de trabajo en beneficio de la comunidad.

- Suspensiones de condena.

- Sustituciones de condena.

Se pretende con ellas evitar los efectos desocializadores que implican las penas privativas de libertad, y hacer, de alguna manera, que la persona condenada puede reparar el daño causado a la sociedad desde esta misma. Los Servicios de Gestión de Penas y Medidas Alternativas, son las unidades administrativas encargadas de la gestión de este tipo de penas (SGIP, 2016). 


\subsection{Libertad condicional}

Tras la reforma penal operada por la Ley Orgánica 1/2015, en vigor desde el 1 de julio del mismo año, la libertad condicional declina su naturaleza de último grado del sistema penitenciario de individualización científica, para convertirse en una modalidad de suspensión de la pena de prisión pendiente de cumplimiento.

A diferencia de la suspensión de penas privativas de libertad previstas en el artículo 80 del Código Penal, la suspensión del resto de prisión dispuesta en el artículo 90 y siguientes de dicho texto puede acordarse respecto de cualquier pena de prisión, independientemente de cuál sea su cuantía, y aplicarse a cualquier penado haya delinquido o no por primera vez.

\subsection{Trabajo a favor de la comunidad}

El trabajo en beneficio de la comunidad es una medida alternativa al ingreso en prisión. Para quienes lo realizan comporta una función reeducativa a la vez que hace algo útil y provechoso para la sociedad.

La persona sometida a esta medida está obligada a invertir un determinado tiempo en el desarrollo de la tarea que se le ha asignado. Entre las muchas ventajas que aporta este tipo de sanción cuenta con la de ser una medida igualitaria que se cumple en libertad y evita por tanto la ruptura con la vida familiar, laboral y social del penado, además de promocionar valores como la solidaridad, la responsabilidad y el bien común.

\subsection{E1 medio abierto}

El medio abierto pretende ser un modelo de referencia en el proceso de incorporación social de las personas que son objeto de la acción penal, a través de la actuación coordinada y armónica de todos los recursos sociales y comunitarios.

Alberga un importante segmento de población penal que, cumpliendo condena, se encuentra en un proceso acreditado de inserción social. Las personas clasificadas en tercer grado de tratamiento disfrutan de un régimen de vida que permite la excarcelación motivada diaria para su integración social, utilizando los recursos comunitarios existentes. 


\subsection{Terceros grados en centros de régimen ordinario}

Penados clasificados en tercer grado de tratamiento y que podrían permanecer en medio ordinario hasta la libertad condicional (que se presume próxima):

- Tercer grado art. 104.4 (enfermos incurables): se les clasifica en el tercer grado, por razones humanitarias y de dignidad personal, a los penados o penadas con enfermedades muy graves o con padecimientos incurables.

- Tercer grado art. 197 (extranjeros): se establece la posibilidad de conceder la libertad condicional a internos extranjeros no residentes legalmente en España, o de españoles residentes en el extranjero para que dicha libertad se disfrute en el país de residencia fijado.

\subsection{Control telemático}

Los medios telemáticos son un conjunto de sistemas electrónicos que las instituciones penitenciarias utilizan para el control de presencia a distancia de personas que se encuentran en el ámbito de sus competencias. $\mathrm{El}$ art. 86.4 del vigente Reglamento Penitenciario posibilita una forma específica de cumplir condena en régimen abierto, sustituyendo el tiempo de estancia mínimo obligatorio en el establecimiento por medios telemáticos $\mathrm{u}$ otros sistemas adecuados de control.

Todos estos sistemas de vigilancia telemática permiten también establecer previamente las restricciones de movimiento que se estimen convenientes en cada caso para hacer compatible la integración social y la seguridad ciudadana.

Este tipo de medidas de vigilancia evitan el ingreso en prisión, tanto de los internos en régimen ordinario como en régimen abierto y de infractores no peligrosos que no hayan cometido delitos graves. Facilitan también que se cumpla la condena en el entorno familiar y social, evitando la desestructuración familiar. Permite, además, que el penado continúe su vida laboral y pueda atender así a la indemnización de la víctima.

\subsection{Centros de inserción social}

Los CIS están destinados a internos que cumplen su pena en régimen abierto o que se encuentran en un proceso avanzado de reinserción (art. 100.2), que están 
en situación de libertad condicional o cumplen medidas alternativas a la pena como trabajo en beneficio de la comunidad. Se gestionan desde estos centros una pluralidad de modalidades, formas y fases de condenas que requieren medios de control y seguimiento idóneos.

Son establecimientos penitenciarios destinados al cumplimiento tanto de las penas privativas de libertad en régimen abierto como de las penas no privativas de libertad establecidas en la legislación vigente, y cuya ejecución se atribuye a la administración penitenciaria. Así mismo, se realiza desde los CIS el seguimiento de los liberados condicionales.

\subsection{Programas en medio abierto}

El medio abierto tiene como fin primordial la reeducación y reinserción social de los penados. La Subdirección General de Tratamiento y Gestión Penitenciaria debe organizar, coordinar y potenciar actuaciones con programas de intervención biopsicosocial y acciones formativo laborales. Para ello, se realiza el diseño, implantación, seguimiento y evaluación de los programas de intervención y tratamiento destinados a los internos en régimen abierto.

Para ello, resulta imprescindible, en primer lugar, el principio de confianza en el interno y la aceptación voluntaria por él mismo de los programas de tratamiento; en segundo lugar, la derivación a recursos externos a través de la integración en los recursos comunitarios y otras redes sociales de apoyo. Esta derivación no podría conseguirse sin la estrecha coordinación e interacción con todos los organismos e instituciones públicas y privadas (ONG, asociaciones y entidades colaboradoras) que actúan en la atención y reinserción de los internos, prestando especial atención de los recursos sociales externos, particularmente en materia de sanidad, educación acción formativa y trabajo.

\section{Fines del tratamiento penitenciario en España}

Los fines del tratamiento penitenciario en el sistema español, se encuentran centrados específicamente en la reeducación y reinserción social, ambos propósitos han sido implementados dentro de los sistemas carcelarios de América Latina que al igual que el español, hoy en día basan la ejecución penal en los fines resocializadores 
que permiten un tratamiento apegado a las normas internacionales de protección de derechos fundamentales de los privados de la libertad.

La Constitución española reafirma en su art. 25.2 que "las penas privativas de libertad y las medidas de seguridad estarán orientadas hacia la reeducación y reinserción social”, por tanto, el tratamiento penitenciario debe ser entendido como el conjunto de actuaciones directamente dirigidas a la consecución de este fin.

El tratamiento penitenciario adquiere de esta manera un papel primordial en el sistema penitenciario, determinando el grado de clasificación y, por tanto, el régimen de vida que tenga el penado durante el cumplimiento de su condena. Frente al carácter estático del sistema progresivo, el sistema de individualización científica incorpora la flexibilidad a través de dos vías: en la aplicación de las actividades de tratamiento de manera individualizada a las necesidades y carencias del recluso y, en segundo lugar, a través de la previsión de la progresión del grado a partir de los criterios subjetivos referidos a la evolución positiva del interno y no de criterios estrictamente objetivos como en las regulaciones anteriores. (Rodríguez, 2013)

\section{Conclusiones y resultados}

A manera de conclusión, habremos de decir que si bien el sistema de ejecución de sanciones en España no es un modelo perfecto pero sí perfectible, que ha servido y sentado las bases para el "novedoso" sistema de ejecución penal en la gran mayoría de países latinoamericanos, que han visto dentro de la figura del juez de vigilancia penitenciaria, la posibilidad de un modelo que ofrece no solo alternativas al uso excesivo de la pena de prisión y con ello los sustitutivos penales que pueden dar paso - a mediano y largo plazo - a la contención de la crisis penitenciaria que tanto ha marcado nuestras cárceles; sino que también es un modelo garantista que permite la inclusión y respeto de los derechos humanos y que pretende terminar con la estigmatización social, pero sobre todo estatal, en que se han abusado y corrompido a miles de personas que han estado en un centro penitenciario, purgando condenas en condiciones verdaderamente lamentables y de las cuales las secuelas son todavía más graves de las que se pretendía sancionar y justificar en un principio. 
ElJVP español ha permitido también que los países latinoamericanos se sumen a los principios que enmarcan el derecho internacional, $\mathrm{y}$ con ello puesto las bases de un sistema jurídico globalizado que pretende estandarizar, en la medida de lo posible, las normas internacionales de respeto a los derechos humanos, el acceso a la justicia y la conceptualización del estado de derecho, así como también de los conceptos de persona, legalidad y pena.

Si bien es cierto que sería absurdo comparar del todo los sistemas de ejecución penal latinoamericanos con los de España, por las distintas formas en que se desarrolla la criminalidad y los muy variados inconvenientes que surgen a la hora de sanear un sistema tan convulso como lo es el sistema carcelario, también es cierto que gracias a países como España, donde se ha trabajado intensamente en la consolidación de un sistema carcelario que busque hacia la pena retributiva y la resocialización, es que en México o Colombia (por citar algunos), hoy se cuenta con figuras judiciales que pretenden dotar al sistema penitenciario de mecanismos para la correcta eficacia y justificación de la prisión. ya no solo como pena, sino un medio de reinserción social.

España también tiene muchos retos, que tienen que ver con la disminución en el uso de la pena y por supuesto que pretenden homologar a sistemas más eficaces como el alemán o en el mejor de los casos como Holanda, que no apuestan hoy, estos últimos, en la imposición de penas, sino en mecanismos de prevención, sanciones alternativas a la prisión y principalmente a la educación social en contra de la comisión de conductas delictivas.

Lo más importante es que el modelo español ha mostrado a los países latinoamericanos que el control judicial no solo tiene que estar centrado en la imposición de una pena privativa de la libertad, sino que además tiene que estar centrado, más que en la pena, en sustitutivos a la misma, y que en ello existe una amplia posibilidad de mecanismos que lo permiten desde el trabajo a favor de la comunidad, el control telemático o bien las penas en libertad vigilada, todo ello en estricto apego a la legalidad y la función judicial de control y vigilancia de un juez. Lo anterior, con el único propósito de poder reeducar, resocializar y reeducar al sujeto que ha delinquido y que además son los mismos propósitos que persiguen 
constitucionalmente países como Colombia y México, y que muy difícilmente sea un objetivo próximo a cumplir.

\section{Referencias}

Berdugo, I. (2016). Lecciones y materiales para el estudio del derecho penitenciario, (pp. 304-308. Tomo VI. Derecho Penitenciario. Madrid: Editorial Iustel.

Cervelló, D. V. (2015). Derecho penitenciario, (p. 121). Valencia, España: Editorial Tirant Lo Blanch.

Foucault, M. (1978). Vigilar y castigar, (p. 314). Madrid, España.

González, J. (2014). Metodología jurídica epistémica. México D.F.: Editorial. Fontamara.

Huertas, O., y Abreu, O. (2007). El derecho al debido proceso y las garantías judiciales en la dimensión internacional de los derechos humanos. Bogotá: Grupo Editorial Ibáñez.

Huertas, O., Trujillo, J. S., y Silvera, A. (2015). Perspectivas de los derechos humanos y la libertad en contextos de sistemas penitenciarios. Análisis Politico, 28(84), 115-134.

Huertas, O. (2015). Sistema penal y hacimiento carcelario Análisis al estado de cosas inconstitucionales en las prisiones colombianas. Revista Jurídica Derecho, 2, 15-24.

Juanatey, C. (2016). Manual de derechopenitenciario, (pp. 241-242). Madrid: Editorial Iustel. Martín, J. (1999). Del juez de vigilancia penitenciaria, (pp. 1089-1091). Tomo V.

Pérez, A. I. (2016). Lecciones materiales para el estudio del derecho penitenciario, (p. 292). Tomo VI. Derecho Penitenciario. En I. Berdugo (edit). Madrid: Iustel.

Pérez, L. (1984). Los derechos fundamentales, (pp. 174-175). España: Editorial Madrid.

Racionero, F. (1999). Derecho penitenciario y privación de libertad. Una perspectiva judicial, (pp. 70-71). Madrid: Editorial Dykinson.

Rivera, I. (coord.). (1999). Tratamiento penitenciario y derechos fundamentales, (p. 312). Editorial J. M. Bosch.

Rodríguez, C. (2013). El sistema penitenciario español ante el siglo XXI, (pp. 30-53). España: Editorial Iustel. España

Romero, G. (2017, enero-junio). Libertad vs. populismo punitivo: ¿deben respetarse los derechos humanos en el proceso penal? A propósito de la nueva declaratoria de estado de cosas inconstitucionales para el sistema penitenciario y carcelario colombiano. Revista Via Inveniendi et Iudicandi, 12(1), 89-117 Recuperado de http://revistas.usantotomas. edu.co/index.php/viei/article/view/3561/3449

Secretaría General de Instituciones Penitenciarias. (2016). Informe general 2015. España: Ministerio del Interior. 
Secretaría General de Instituciones Penitenciarias. (s.f.). El medio abierto. Ministerio del Interior. Recuperado de http://www.institucionpenitenciaria.es/web/portal/cumplimientoMedioAbierto/controlTelematico.html

Valderrama, I. (2016, julio-diciembre). E1 principio de congruencia en el proceso penal. Revista Via Inveniendi et Iudicandi, 11(2), 159-180. Recuperado de http://revistas. usantotomas.edu.co/index.php/viei/article/view/3280/3092 